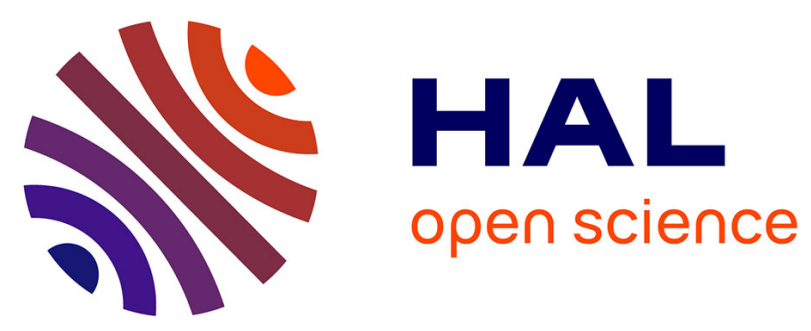

\title{
Sudden Death Related to Toxicity in a Patient on Capecitabine and Irinotecan Plus Bevacizumab Intake: Pharmacogenetic Implications
}

Laetitia Dahan, Joseph Ciccolini, Alexandre Evrard, Litaty Mbatchi, Jack Tibbitts, Pauline Ries, Emmanuelle Norguet, Cédric Mercier, Athanassios Iliadis, L'Houcine Ouafik, et al.

\section{To cite this version:}

Laetitia Dahan, Joseph Ciccolini, Alexandre Evrard, Litaty Mbatchi, Jack Tibbitts, et al.. Sudden Death Related to Toxicity in a Patient on Capecitabine and Irinotecan Plus Bevacizumab Intake: Pharmacogenetic Implications. Journal of Clinical Oncology, 2012, 30 (4), pp.e41 - e44. 10.1200/JCO.2011.37.9289 . hal-01707728

\section{HAL Id: hal-01707728 \\ https://hal-amu.archives-ouvertes.fr/hal-01707728}

Submitted on 13 Feb 2018

HAL is a multi-disciplinary open access archive for the deposit and dissemination of scientific research documents, whether they are published or not. The documents may come from teaching and research institutions in France or abroad, or from public or private research centers.
L'archive ouverte pluridisciplinaire HAL, est destinée au dépôt et à la diffusion de documents scientifiques de niveau recherche, publiés ou non, émanant des établissements d'enseignement et de recherche français ou étrangers, des laboratoires publics ou privés. 


\section{Sudden Death Related to Toxicity in a Patient on Capecitabine and Irinotecan Plus Bevacizumab Intake: Pharmacogenetic Implications}

\section{Introduction}

Capecitabine is an oral alternative to fluorouracil (FU) frequently administered as part of combination therapies in digestive oncology. This prodrug is designed to be activated through a triple enzymatic process, which eventually generates FU in tumors. A genetic polymorphism that affects dihydropyrimidine dehydrogenase (DPYD), which is the enzyme responsible for the liver detoxification of $\mathrm{FU}$, is the canonical syndrome identified as a possible pharmacogenetic issue with capecitabine. ${ }^{1,2}$ However, an early step in the hepatic activation of capecitabine requires cytidine deaminase (CDA), which is a ubiquitous enzyme also affected by several genetic polymorphisms. ${ }^{3,4}$ In digestive oncology, high interpatient variability observed in CDA activity is a rising concern with gemcitabine that is detoxified in the liver by deamination. Downregulated CDA has been associated with overexposure and subsequent severe toxicities on gemcitabine treatment. ${ }^{5-8}$ Because CDA also plays a critical role in the activation of capecitabine to FU, the reported variability in its activity could markedly affect FU formation, with either a loss of efficacy (CDA-deficient patients) or increased toxicities (CDA-ultrametabolizer patients). Little data are available about the impact of CDA status on the clinical outcome with capecitabine treatment. We previously published the case of a patient with increased CDA activity who experienced severe toxicities after capecitabine administration. ${ }^{9}$ More recently, it was reported that the deleted allele rs3215400 across the CDA promoter could be predictive of severe hand-foot syndrome in patients treated with capecitabine, ${ }^{10}$ although a previous report failed to evidence this association, ${ }^{11}$ which thus illustrated the conflictual genotype-tophenotype relationships with $\mathrm{CDA} .{ }^{12}$

\section{Case Report}

This patient case was that of a 57-year-old white man treated for metastatic colorectal cancer. On first screen, anemia was found, and endoscopy with biopsy revealed a well-differentiated adenocarcinoma. The patient was initially treated by surgery in 2007 with colectomy and hepatic metastasectomy. Because dihydropyrimidine dehydrogenase (DPD) deficiency is a condition associated with increased risk of life-threatening toxicities in patients scheduled for an FU-based regimen, DPD status was evaluated according to the standard uracil-todihydrouracil plasma ratio determination, as described previously. ${ }^{1}$ After preliminary assessment of the functional status of DPD showed no evidence of deficiency (ie, uracil-to-dihydrouracil ratio $<2$ ), standard adjuvant chemotherapy with infusional FU, leucovorin, and oxaliplatin was initiated. Treatment was well tolerated. However, at the end of the adjuvant therapy, new lung and liver metastases were observed, and the patient was treated with infusional FU, leucovorin, and irinotecan in combination with bevacizumab. This

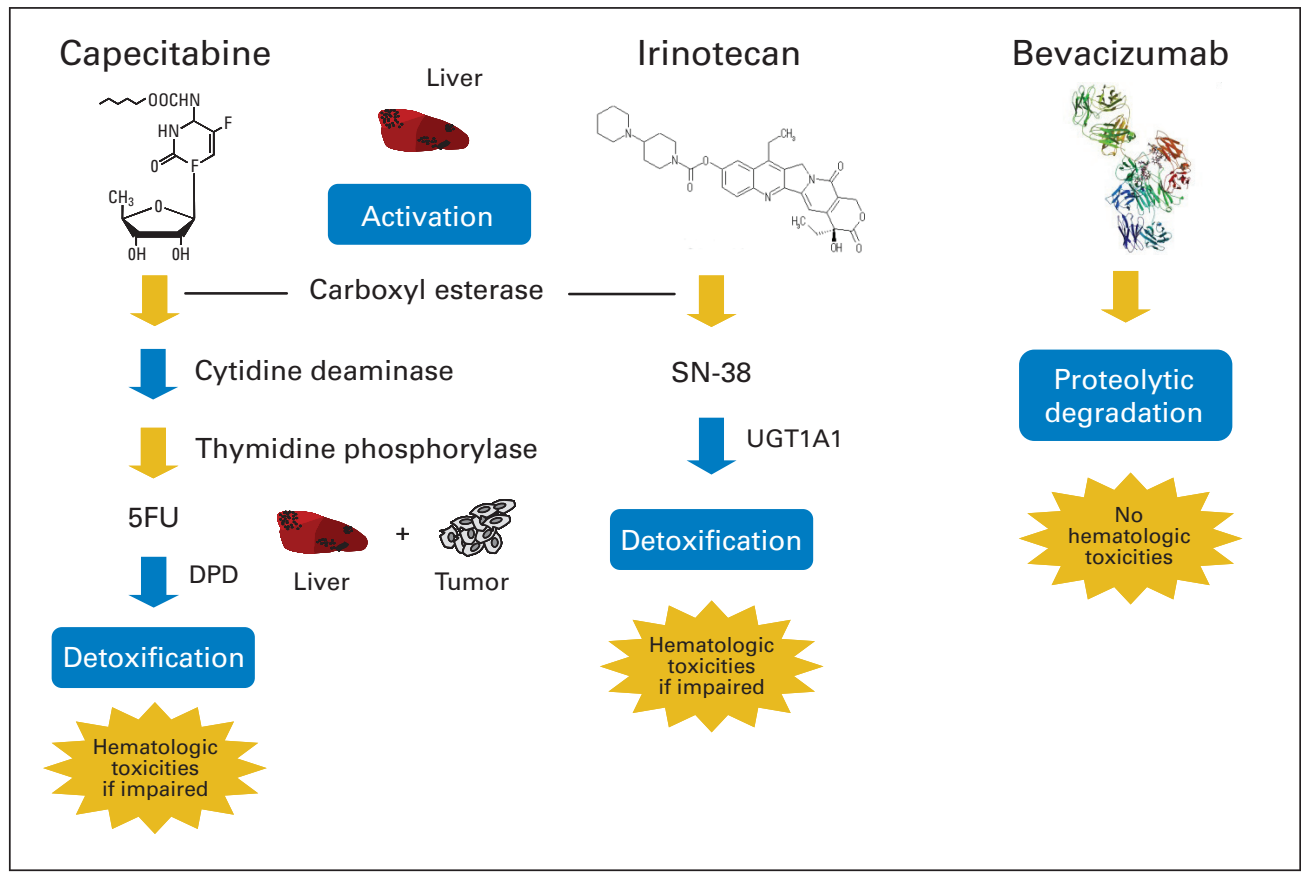

Fig 1. 


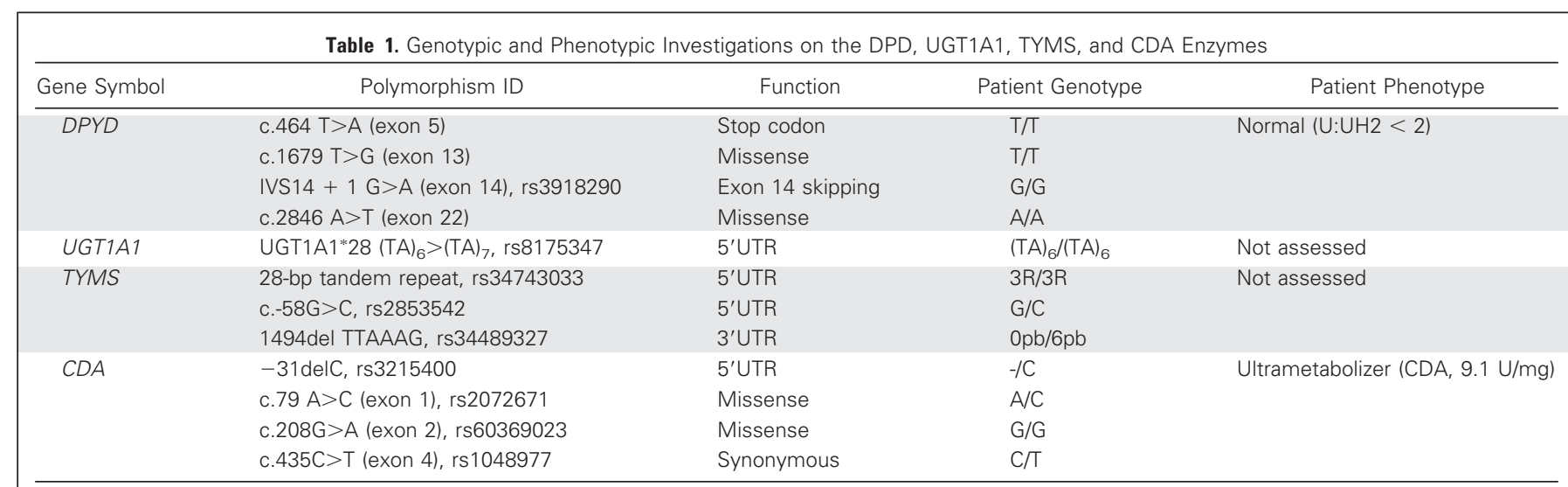

Abbreviations: bp, base pair; CDA, cytidine deaminase; DPD, dihydropyrimidine dehydrogenase; ID, identifier; TYMS, thymidylate synthase; U:UH2, uracil-todihydrouracil ratio; UGT1A1, uridine glucuronyl transferase 1A1; UTR, untranslated region.

combination was also well tolerated with no signs of systemic toxicity. However, after 32 chemotherapy cycles over a span of 2 years, the central catheter was removed as a result of cutaneous intolerance. The patient was to be treated with a protocol of capecitabine plus irinotecan and bevacizumab as follows: irinotecan $200 \mathrm{mg} / \mathrm{m}^{2}$ (total dose, $400 \mathrm{mg}$ ) on days 1 and 21, capecitabine $1,000 \mathrm{mg} / \mathrm{m}^{2}$ twice daily from days 1 to 14 (total dose, $3500 \mathrm{mg} / \mathrm{d}$ ), and bevacizumab 7.5 $\mathrm{mg} / \mathrm{kg}$ (total dose, $775 \mathrm{mg}$ ) on days 1 and 21 . However, soon after the treatment began (day 7), the patient was rehospitalized as a result of severe toxicities (eg, grade 4 diarrhea, grade 4 neutropenia, and sepsis). Capecitabine intake was immediately discontinued. Despite the appropriate symptomatic treatment (clavulanic acid, amikacin, and filgrastim), the condition of the patient quickly deteriorated with a fatal outcome on day 12.

\section{Discussion}

Because genetic polymorphisms that affect the disposition of anticancer agents are now a major issue in clinical oncology, ${ }^{13}$ we investigated whether dysregulation of the various enzymes involved in the activation/deactivation patterns of the administered drugs could have been responsible for the death of the patient (Fig 1; SN-38, toxic metabolite 7-ethyl-10-hydroxy-camptothecin). The investigations assessed both the functional and genetic status of the patient, with the results listed in Table 1. Because this patient had tolerated extensive irinotecan exposure over 2 years, it was believed to be unlikely that the inherited pharmacogenetic syndromes that affect UGT1A1 (eg, $U G T 1 A 1^{*} 28$ allelic variant) usually associated with severe toxicities with irinotecan treatment could have explained this fatal outcome. ${ }^{14}$ Postmortem genetic investigations confirmed that this patient was bearing the $U G T 1 A 1^{*} 1$ common genotype $\left([\mathrm{TA}]_{6} /[\mathrm{TA}]_{6}\right)$ and not the allelic variant. Bevacizumab was also eliminated as the cause for this toxicity on the basis of the evidence that the observed toxicities in this patient were inconsistent with those previously described for this drug $^{15}$ and the knowledge that the patient had tolerated extensive previous treatment with bevacizumab. Therefore, the focus of the investigation turned to capecitabine. The mechanism by which capecitabine may cause serious toxicities may be related to increased FU exposure that results from either impaired detoxification by DPD or increased formation of FU from capecitabine. DPD is the rate-limiting enzyme for detoxification of fluoropyrimidine drugs, and genetic polymorphism that affects DPYD is a paradigmatic pharmacogenetic syndrome associated with early severe toxicities with FU derivatives. ${ }^{16,17}$ As described previously, the patient had been identified as non-DPD deficient, which was a finding that was consistent with his tolerance of a previous regimen of infusional fluorouracil, leucovorin, and oxaliplatin and then fluorouracil, leucovorin, and irinotecan. To further confirm this nondeficient phenotype, a retrospective assessment of DPYD genetic status showed none of the genetic variations (ie, exon $5464 \mathrm{~T}>\mathrm{A}$, exon $131679 \mathrm{~T}>\mathrm{G}$, exon $14 \mathrm{IVS} 14+1 \mathrm{G}>\mathrm{A}$, and exon $222846 \mathrm{~A}>\mathrm{T}$ ) usually associated with DPD impairment. ${ }^{18}$ Thus, an inherited inability to detoxify circulating FU was not the cause of the death related to toxicity. Additionally, we investigated polymorphisms in the $5^{\prime}$ and $3^{\prime}$ untranslated regions of the TYMS gene that are responsible for the dysregulation of thymidylate synthase and were previously associated with increased toxicities in patients treated with capecitabine. ${ }^{19}$ Similar to $D P Y D$, no functionally relevant polymorphisms were found on TYMS, and the genotype was typically associated with normal thymidylate synthase expression, ${ }^{20,21}$ which was an

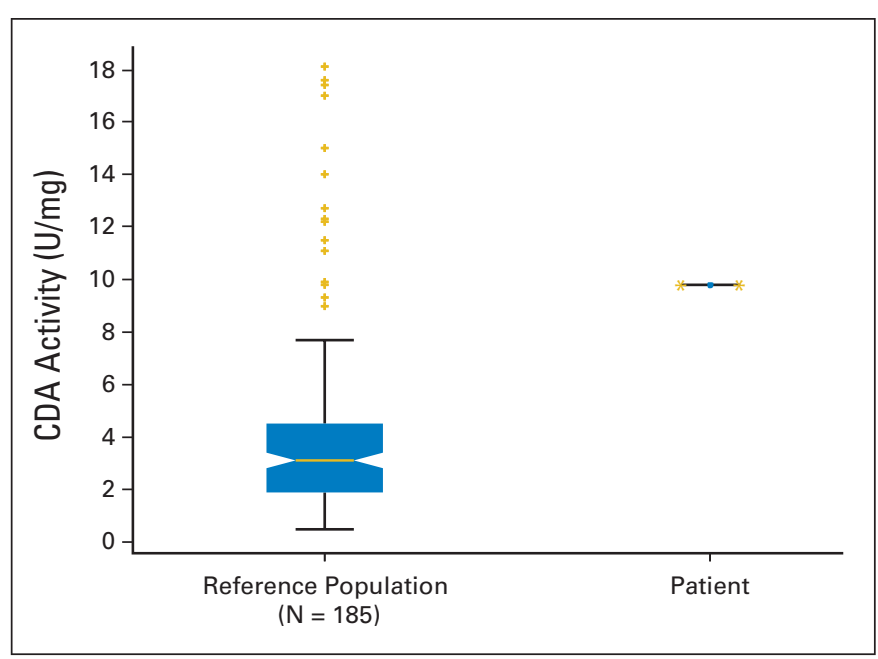

Fig 2. 
observation that implicated increased hepatic conversion of the prodrug capecitabine to $\mathrm{FU}$ as the last remaining cause of the lethal toxicities. As a triple prodrug, capecitabine is rationally designed to be preferentially activated to FU by carboxylesterase, CDA, and finally thymidine phosphorylase. ${ }^{22}$ Because our group had previously investigated $C D A$ dysregulations as a means to identify deficient individuals likely to develop severe toxicities with gemcitabine, ${ }^{6,8}$ we have already observed that some patients displayed particularly increased CDA activities and, thus, could be considered CDA ultrarapid metabolizers (UMs). Thus, we hypothesized that the patient described in this article could have been a UM, which resulted in increased formation of FU and subsequent lethal toxicities. To test this hypothesis, a phenotypic investigation was first carried out to establish the functional CDA status of this patient. An evaluation of CDA residual activity in serum was performed as a surrogate for CDA status. ${ }^{8}$ The CDA activity of the patient was $9.1 \mathrm{U} / \mathrm{mg}$, which was $193 \%$ higher than the median value recorded in patients with cancer at our institute (mean, $3.9 \pm 3.3$ $\mathrm{U} / \mathrm{mg} ; \mathrm{n}=185$ ). Regarding the general distribution in CDA activities normally observed (Fig 2), this patient was unequivocally classified as a UM because his CDA value differed statistically from the reference population $\left(\mathrm{t}_{\mathrm{obs}}>\mathrm{t}_{\text {student }} ; \alpha=0.01 ; \mathrm{n}=184\right.$ ), which confirmed our hypothesis. Additional genetic investigations showed several polymorphisms on the CDA gene. Heterozygocity was found on the 435CT and 79AC mutations. However, conflicting reports of the genotype-to-phenotype relationships of these polymorphisms prevented making a conclusion. ${ }^{12}$ More interestingly, the patient was also heterozygous for the rs3215400 single nucleotide polymorphism that corresponds to a $\mathrm{C}$ insertion at the -31 position. Caronia et $\mathrm{al}^{10}$ have recently shown that this insertion was associated with enhanced CDA expression, probably through the creation of an additional binding site for the transcriptional factor E2F, with a possible impact on increased activity. Overall, both our functional and genetic data strongly suggested, for the first time to our knowledge, that deregulated CDA with subsequent extensive activity could be the initiating factor for death related to toxicity in a capecitabine-treated patient, which is likely produced by higher amounts of circulating FU than normally expected from the standard dosage. Although this patient did not have an inherited deficiency in DPD, the role of DPD as a rate-limiting, saturable downstream enzyme in the elimination of fluoropyrimidines may have prevented this patient from detoxifying the unexpectedly high levels of FU generated from capecitabine, which led to unrecoverable toxicities and death eventually.

Improving the use of anticancer drugs through personalized medicine is of great interest in clinical oncology. Deregulations and genetic polymorphisms that affect TPMT, UGT1A1, DPYD, Cyp2D6, and $C D A$ are regularly associated with highly variable pharmacokinetics and poor clinical outcomes with mercaptopurine, irinotecan, FU plus capecitabine, tamoxifen, and gemcitabine, respectively. ${ }^{23,24} \mathrm{We}$ previously reported the first case of death related to toxicity, to our knowledge, in a patient who was undergoing a capecitabine plus oxaliplatin protocol related to a DPYD 1896TC polymorphism with subsequent profound DPD deficiency. ${ }^{1}$ Consequently, the DPYD genetic polymorphism is now fully recognized as a major risk for the development of severe/lethal toxicities with capecitabine, and known DPD deficiency is a contraindication with this drug. Because capecitabine is usually a well-tolerated oral drug, it is often seen as a safe and convenient alternative in patients who experienced FU-related toxicities. However, in this article, we demonstrated that patients without
DPD deficiency, who, furthermore, proved to fully tolerate FU in the past, are at risk for FU lethal toxicities as a result of CDA UM status if administered oral capecitabine. Although additional clinical investigations are required to fully confirm the implication of CDA in unexpected, severe toxicities with this drug, this report suggests that, beside the genetic polymorphisms affecting DPYD, deregulations of CDA should be screened at bedside in patients scheduled for capecitabinebased therapy.

\section{Laetitia Dahan}

La Timone University Hospital of Marseille, Aix-Marseille Univ, CRO2 UMR 911, Marseille, France

\section{Joseph Ciccolini}

Hôpital Nord; La Timone University Hospital of Marseille; Aix-Marseille Univ, CRO2 UMR 911, Marseille, France

\section{Alexandre Evrard and Litaty Mbatchi \\ University-Hospital of Nîmes, Nîmes, France}

Jack Tibbitts

Genentech, San Francisco, CA

\section{Pauline Ries and Emmanuelle Norguet}

La Timone University Hospital of Marseille, Marseille, France

\section{Cedric Mercier and Athanassios Iliadis}

Aix-Marseille Univ, CRO2 UMR 911, Marseille, France

\section{L'Houcine Ouafik}

Nord University Hospital of Marseille; Aix-Marseille Univ, CRO2 UMR 911, Marseille, France

\section{Bruno Lacarelle and Jean-Francois Seitz}

La Timone University Hospital of Marseille, Aix-Marseille Univ, CRO2 UMR 911, Marseille, France

\section{AUTHORS' DISCLOSURES OF POTENTIAL CONFLICTS OF INTEREST}

Although all authors completed the disclosure declaration, the following author(s) indicated a financial or other interest that is relevant to the subject matter under consideration in this article. Certain relationships marked with a "U" are those for which no compensation was received; those relationships marked with a " $C$ " were compensated. For a detailed description of the disclosure categories, or for more information about ASCO's conflict of interest policy, please refer to the Author Disclosure Declaration and the Disclosures of Potential Conflicts of Interest section in Information for Contributors.

Employment or Leadership Position: Jack Tibbitts, Genentech (C) Consultant or Advisory Role: Jean-Francois Seitz, Bayer (C) Stock Ownership: Jack Tibbitts, Roche Honoraria: None Research Funding: None Expert Testimony: None Other Remuneration: None

\section{REFERENCES}

1. Ciccolini J, Mercier C, Dahan L, et al: Toxic death-case after capecitabine + oxaliplatin (XELOX) administration: Probable implication of dihydropyrimidine deshydrogenase deficiency. Cancer Chemother Pharmacol 58:272-275, 2006

2. Mercier C, Ciccolini J: Severe or lethal toxicities upon capecitabine intake: Is DPYD genetic polymorphism the ideal culprit? Trends Pharmacol Sci 28:597598,2007

3. Giovannetti $E$, Laan $A C$, Vasile $E$, et al: Correlation between cytidine deaminase genotype and gemcitabine deamination in blood samples. Nucleosides Nucleotides Nucleic Acids 27:720-725, 2008

4. Schröder JK, Kirch C, Seeber S, et al: Structural and functional analysis of the cytidine deaminase gene in patients with acute myeloid leukaemia. $\mathrm{Br} J$ Haematol 103:1096-1103, 1998

5. Sugiyama E, Kaniwa N, Kim SR, et al: Pharmacokinetics of gemcitabine in Japanese cancer patients: The impact of a cytidine deaminase polymorphism. J Clin Oncol 25:32-42, 2007 
6. Mercier C, Raynal C, Dahan L, et al: Toxic death case in a patient undergoing gemcitabine-based chemotherapy in relation with cytidine deaminase downregulation. Pharmacogenet Genomics 17:841-844, 2007

7. Tibaldi $C$, Giovannetti $E$, Tiseo $M$, et al: Correlation of cytidine deaminase polymorphisms and activity with clinical outcome in gemcitabine-/ platinum treated advanced non-small-cell lung cancer patients. Ann Oncol 2011 EPub, Jun 7

8. Ciccolini J, Dahan L, André N, et al: Cytidine deaminase residual activity in serum is a predictive marker of early severe toxicities in adults after gemcitabinebased chemotherapies. J Clin Oncol 28:160-165, 2010

9. Mercier C, Dupuis C, Blesius A, et al: Early severe toxicities after capecitabine intake: Possible implication of a cytidine deaminase extensive metabolizer profile. Cancer Chemother Pharmacol 63:1177-1180, 2009

10. Caronia D, Martin M, Sastre J, et al: A polymorphism in the cytidine deaminase promoter predicts severe capecitabine-induced hand-foot syndrome. Clin Cancer Res 17:2006-2013, 2011

11. Ribelles N, López-Siles J, Sánchez A, et al: A carboxylesterase 2 gene polymorphism as predictor of capecitabine on response and time to progression. Curr Drug Metab 9:336-343, 2008

12. Mercier $C$, Dahan $L$, Ouafik $L$, et al: Letter to the editor: Pharmacokinetics of gemcitabine in non-small-cell lung cancer patients: Impact of the 79A $>C$ cytidine deaminase polymorphism. Eur J Clin Pharmacol 66:959-960, 2010

13. Marsh S, McLeod HL: Pharmacogenomics: From bedside to clinical practice. Hum Mol Genet 15:R89-93, 2006

14. Cecchin $E$, Innocenti F, D'Andrea $M$, et al: Predictive role of the UGT1A1, UGT1A7, and UGT1A9 genetic variants and their haplotypes on the outcome of metastatic colorectal cancer patients treated with fluorouracil, leucovorin, and irinotecan. J Clin Oncol 27:2457-2465, 2009
15. Mulder K, Scarfe A, Chua N, et al: The role of bevacizumab in colorectal cancer: Understanding its benefits and limitations. Expert Opin Biol Ther 11:405413, 2011

16. van Kuilenburg AB, Klumpen HJ, Westermann AM, et al: Altered dihydropyrimidine dehydrogenase activity associated with mild toxicity in patients treated with 5-fluorouracil containing chemotherapy. Nucleosides Nucleotides Nucleic Acids 27:726-732, 2008

17. Ezzeldin HH, Diasio RB: Predicting fluorouracil toxicity: Can we finally do it? J Clin Oncol 26:2080-2082, 2008

18. Ciccolini J, Gross E, Dahan L, et al: Routine dihydropyrimidine dehydrogenase testing for anticipating 5-fluorouracil-related severe toxicities: Hype or hope? Clin Colorectal Cancer 9:224-228, 2010

19. Shahrokni A, Rajebi MR, Saif MW: Toxicity and efficacy of 5-fluorouracil and capecitabine in a patient with TYMS gene polymorphism: A challenge or a dilemma? Clin Colorectal Cancer 8:231-234, 2009

20. Largillier $\mathrm{R}$, Etienne-Grimaldi $\mathrm{MC}$, Formento $\mathrm{JL}$, et al: Pharmacogenetics of capecitabine in advanced breast cancer patients. Clin Cancer Res 12:5496-5502, 2006

21. Nief N, Le Morvan V, Robert J: Involvement of gene polymorphisms of thymidylate synthase in gene expression, protein activity and anticancer drug cytotoxicity using the NCl-60 panel. Eur J Cancer 43:955-962, 2007

22. Malet-Martino $M$, Martino R: Clinical studies of three oral prodrugs of 5-fluorouracil (capecitabine, UFT, S-1): A review. Oncologist. 7:288-323, 2002

23. Ciccolini J, Mercier $C$, Dahan $L$, et al: Integrating pharmacogenetics into gemcitabine dosing-Time for a change? Nat Rev Clin Oncol 8:439-444, 2011

24. Houtsma D, Guchelaar HJ, Gelderblom H: Pharmacogenetics in oncology: A promising field. Curr Pharm Des 16:155-163, 2010

DOI: 10.1200/JCO.2011.37.9289; published online ahead of print at www.jco.org on December 19, 2011 